\title{
Effectiveness of Health and Safety Training for Municipal Waste Collectors: A Case Study from Galle, Sri Lanka
}

\author{
T. Rajapaksha ${ }^{*}$, Saliya De Silva ${ }^{1}$, B.F.A. Basnayake ${ }^{2}$, Lahiru N. Jayakody ${ }^{3}$ \\ R.T.K. Ariyawansha ${ }^{2}$, A.N. Siriwardena ${ }^{2}$, Jos Nolle ${ }^{4}$, and Kyla Pennie ${ }^{5}$
}

\author{
Postgraduate Institute of Agriculture \\ University of Peradeniya \\ Sri Lanka
}

\begin{abstract}
Municipal waste collectors are exposed to numerous hazardous substances during the process of collection, transportation and the disposal of municipal solid wastes, resulting in occupational health and safety risks including mortality and morbidity. An efficient and safe municipal solid waste collection system is vital to protect the environment, the community and the workers involved. Therefore, a training module was developed based on the needs analysis, and after conducting a series of training and awareness programmes, personal protective equipment was distributed to all the 115 municipal waste collectors in Galle Municipal Council, the provincial capital of Southern Province of Sri Lanka. The objective of this study was to determine the effectiveness of those project interventions. A questionnaire survey, key informant discussions and expert observations were used as primary data collection tools, while secondary data were gathered from various reports. Knowledge, Attitudes, Practices (KAP) questionnaire was used to evaluate the conditions of 115 municipal waste collectors before and after conducting the training programme and distributing the personal protective equipment. The interventions made by conducting the training programme described in this study had effectively created a significant improvement in knowledge, attitude and practices of the respondents $(p<0.05)$. Personal protective equipment distributed has resulted in an increase of dignity among the waste collectors giving them recognition by both Galle Municipal Council and the general public of the area.
\end{abstract}

Keywords: Municipal Waste Collectors, Occupational Safety and Health, Personal Protective Equipment, Training and Developmen

\footnotetext{
Faculty of Economics, Saga University, Japan

Department of Agricultural Engineering, Faculty of Agriculture, University of Peradeniya, Sri Lanka

Scientist, National Bio-energy Center, National Renewable Energy Lab, Golden, Colorado, USA

Seneca - Toronto, Canada

Niagara College, Fonthill, Ontario, Canada

* Author of correspondence : teennr@gmail.com
} 


\section{INTRODUCTION}

Waste disposal has become a burning issue in all parts of the world, and Sri Lanka is not an exception. In Sri Lanka, urban solid waste disposal is a responsibility of the municipal councils. The waste collection system of Galle Municipal Council (GMC) daily collects about 40 tons of solid waste covering an area of 1,742.4 ha. Collections from door steps and specified points are the common methods of household waste collection in GMC. In a dayto-day schedule, the Municipal Waste Collectors (MWCs) are dealing with collecting of waste, sweeping streets, cleaning drains, loading and unloading of waste for sorting, composting and landfilling or burning of waste.

Approximately 4,000 occupational accidents have been reported annually in Sri Lanka. As a result 600,000 working days are estimated to be lost (ILO, 2009). Sri Lankan Ministry of Health (2011) reported that nearly $15 \%$ of the total admissions to Colombo National Hospital are due to occupational injuries. Although specific figures were not available, it is well recognized that MWCs are often subjected to occupational accidents. In GMC, almost one half of the urban wastes are collected, which are in a mixed state. Since, they are not separated at the point of disposal, metal particles (e.g. nails, needles, etc.), broken glass particles, chemicals, and other hazardous substances can cause serious injuries to the MWCs. For instance, Mudalige and Dharmathilake (2000) reported that skin cuts and needle prick injuries are common among the MWCs attached to the Western Province of Sri Lanka. They also pointed out that the health problems like back pain, traumatic injuries, itchy rash, cough, wounds and exposure to toxins are quite common among the Western Province MWCs. A study conducted in Colombo had found that about $40 \%$ of the waste collectors suffer from various injuries and diseases but had not been recorded to have received proper medical treatment (Silva, 1987). Local Authorities had not provided them with the Personal Protective Equipment (PPE) such as gloves, boots and raincoats which are essential during such work. Cointreau (2006) has mentioned that waste collectors in the developing countries are more exposed to direct contact of waste than there counterparts in high income countries. They are more susceptible to parasitic and enteric infections and viral infections such as hepatitis and HIV due to unsafe nature of waste handling. A study in Denmark had found that the relative risks of waste collectors falling sick are high compared to the total workforce (NIOSH, 1985). Out of the waste collection related injuries, $29.8 \%$ were reported as fatal injuries in 2010, and waste collection was reported to be the seventh most dangerous job in the United States (Biderman, 2010).

Occupational health risks are attached with the Municipal Solid Waste (MSW) management process, specifically during handling, processing, and disposal stages. The waste collectors who are regularly involved in handling waste are highly exposed to organic dusts and bio aerosols which make them vulnerable to pulmonary infections such as asthma (Poulsen et al. 1995a). Gastro-intestinal problems, organic dust toxic syndrome (influenza, cough, headache), and irritation of the eyes as reported among collectors who work with biodegradable fraction of the domestic waste. Visual fatigue and musculoskeletal problems are also common among the collectors. In their article, Ruffner-Press et al., (1975) have reported that the waste collectors in Geneva have an excess risk for chronic bronchitis. Mustajbegovic et al., (1994) have concluded that the prevalence of chronic respiratory problems were higher among the sanitation workers than other workers. Among the sanitation workers, smokers have a high prevalence of chronic cough, chronic phlegm and chest tightness than the nonsmokers in that group. Berthier (2003) mentioned that there is an association among garbage related work and social exclusion which lead waste collectors highly vulnerable to poor health care and risks associated with the social and cultural environment. Accordingly, there 
is a high occurrence rate of occupational accidents due to unsafe nature of the work. Wickramathilake (2011) has reported that only $1 \%$ of the work related accidents were recorded in Sri Lanka. According to him, prevalence of occupational hazards could be much higher as they are hardly recorded as "work related diseases". Sri Lanka is handicapped with a trusted data source on occupational hazards, accidents, and diseases due to the lack of the proper recording mechanism and research on this subject, and particularly related to waste collectors.

Even though it seems that waste collection is just a labouring job, it involves a lot of occupational health hazards. Unsafe acts of the employees, working environment and management practices are the three main factors which cause occupational accidents. Research has revealed that training and education has a positive impact on health and safety practices of the workers (Robson et al., 2012). Expert advisory panel on Occupational Safety and Health (OSH) in Canadian Ministry of Labour has mentioned a multi-faceted approach consisting of training, management commitment, worker participation, influence on social norms, and creating a process to identify and remove hazards that are necessary to improve OSH (OML, 2010).

A project titled "Working towards Achievable and Sustainable Training for the Environment (WASTE), Galle, Sri Lanka", funded by the Niagara College, Canada in collaboration with Solid Waste Management Research Unit (SWMRU), University of Peradeniya, Technical College, Galle and $\mathrm{GMC}^{6}$, was designed and implemented from the year 2009 upwards. The aims of the project were to design and conduct a training programme and distribute PPE to minimize health and safety risks for MWCs in GMC. This study was undertaken to evaluate the outcomes of these project interventions. The study specifically aims to determine the changes in knowledge, attitudes and behaviour among the MWCs in the GMC,

\section{METHODOLOGY}

All 115 MWCs attached to the GMC were considered as the study population. They comprised of five female workers and 110 male workers. Several methods were used to collect data including Knowledge, Attitude and Practices (KAP) surveys, key informant interviews, focused group discussions and expert observations. Key informant interviews were conducted with the office bearers namely the Mayor, Commissioner, Engineer, Public Health Inspectors, and Medical Officer of Health. This study was conducted using the five following steps.

1. Identification of health and safety needs of MWCs

2. Design a training module on health and safety measures to be adopted in waste collection

3. Design and or select PPE (a health and safety uniform) to MWCs

4. Train MWCs on health and safety measures

5. Training evaluation

Data collection was conducted at three stages namely need analysis, training outcome evaluation and the impact evaluation. KAP survey model focused on measuring before and

\footnotetext{
${ }^{6} \mathrm{GMC}$ is the administration centre of the provincial capital of Southern Province
} 
after effects of the health and safety interventions carried out by the project. The KAP survey questionnaire consisted of both positive and negative Likert scale questions: 15 on knowledge on health and safety on waste handling, 12 on attitudes towards health and safety concerns, and 12 on behavioural practices respectively. KAP survey questionnaire was validated by an expert panel. An interview schedule was used to identify managerial perspectives on MWC's strengths, weaknesses and problems. In addition in-depth interviews were conducted to get a realistic understanding about various aspects associated with working conditions. Focused group discussions were conducted with MWCs aiming at identifying qualitative aspects of MWCs and to prioritize their needs. Work behaviours of MWCs were observed while collecting, lifting, and transporting at disposal sites, markets, and road sides.

The training program was conducted and PPE (gloves, safety helmet, rain coat, overall uniform, safety jacket and boots) was distributed with the objective of improving the knowledge and skills of MWCs, ensure a safe work environment, and a sustainable waste management system. All the PPE were selected considering the tropical environmental conditions as well as the needs of the profession. The training module comprised of 23 hours of training including facilitated discussions, group learning methods, and a field visit. Training module focused on facilitating MWCs to acquire knowledge and skills relevant to their job duties and responsibilities, waste categorization, recycling, health and safety measures for MWCs, different waste collecting systems, equipment and machinery training, landfill pre-treatment methods and introduce ways to uplift living standards of MWCs in terms of acquiring knowledge on human rights, time management, leadership skills, resource management and self-employment opportunities.

Subsequently a post-test was conducted using the same KAP survey questionnaire, eight months after conducting the training programme. This was intended to assess the impact of the training programme on the level of knowledge, attitudes and behaviour of the MWCs. In addition to that expert observations of the onsite workers and the key informant discussions were conducted with the Mayor and the supervisors to triangulate the KAP survey findings.

Data analysis was done using quantitative and qualitative statistics. SPSS 20 was used to analyse data. The sum of the scores of knowledge, attitudes and practices was used to compare the effects of intervention. Internal consistency of the Likert scales in KAP survey questionnaire was tested using Cornbach alpha statistics. The total scores of before and after the intervention were tested for normality distribution by using one sample KolmogorovSmirnov test. As the scores were not following the normal distribution, a non-parametric, Wilcoxon sign rank test was used to compare before and after effects of the interventions. This test was selected as it provides indications of both magnitude and direction. All the respondents were equally treated throughout the research respecting human rights, as equal rights for all.

\section{RESULTS AND DISCUSSION}

The majority $(66 \%)$ of the respondents were above 40 years of age. Majority of the respondent MWCs (84\%) had only primary level education. However, their literacy level was good, which facilitated the implementation of the training programme. Though the waste collection seems to be an unpleasant job performed by members of the socially marginalized groups, a substantial number of the respondents $(51 \%)$ who regularly engaged in waste collection were satisfied with their job. According to them, permanent nature of the 
employment, eligibility to privileges like a pension scheme, employee trust fund (ETF), monthly salary and proximity of their work locations are the main reasons for their satisfaction. The findings also revealed that almost one half $(44 \%)$ of the respondents are willing to let their children engaged in the same occupation.

More than one third of the respondents (36\%) indicated that the administrative structure was not supportive. Most of them indicated that the administration does pay little attention to their grievances. For instance, collectors have not been issued an identity card, thus the workers who collect waste in the morning shift, starting around 5.00 am have to face inconveniences from security officers. They have also failed to provide uniforms, gloves and soap regularly to the MWCs.

\section{Pre and post KAP survey findings}

The results of post-KAP survey were compared with the results from data gathered in the baseline (pre-KAP) survey. The pre-training and post-training scores of the respondents were analysed using the Wilcoxon sign rank test. Table 1 presents the changes in median values in pre and post-training KAP surveys. As shown in Table 1, according to Wilcoxon sign rank test, the health and safety intervention made a statistically significant $(p<0.05)$ improvement in MWC's knowledge, attitudes and work practices. There was a significant reduction in the number of risky work practices on health and safety measures on waste management too, which will be discussed further in the next section.

Table 1. Median knowledge, attitudes, safe work practices and risky work practices

\begin{tabular}{|c|c|c|c|}
\hline \multirow{2}{*}{ Attribute } & \multicolumn{2}{|c|}{ Median Score } & \multirow[t]{2}{*}{ p-value } \\
\hline & Before Project & After Project & \\
\hline Knowledge & 28 & 40 & 0.000 \\
\hline Attitudes & 21 & 25 & 0.000 \\
\hline Safe work behaviours & 7 & 10 & 0.000 \\
\hline Risky work behaviours & 5 & 4 & 0.000 \\
\hline
\end{tabular}

According to Table 1, interventions made by conducting the training programme have effectively created a significant improvement in knowledge, attitudes and practices of the respondents, while reducing their risky behaviour. To sustain the progress achieved through acquisition of new knowledge, skills, and attitudes as well as to induce the respondents to adhere to safe practices, distribution of PPE (safety gears) was considered important. The potential barriers to the use of safety gears were the negative attitudes about the outcome, perceptions on risks, time pressure and peer acceptability. Training programme implemented had helped to overcome these barriers, and as a result the respondents continued to use the PPE. Geer et al., (2006) also proved that the self-protective behaviours work well, when the worker feels that they are informed about the risks, and believe that precautionary methods are effective and has a clearer perception about their own ability to avoid or control exposure. 


\section{Work behaviours of MWCs}

Work behaviours were examined to identify the safe work practices and the risky work practices of the MWCs, as the project intervention aimed to strengthen the safe work behaviours while reducing the risky work behaviours. The pre-KAP survey findings revealed that the majority $(77 \%)$ of the respondents consume foods during the waste collection process which increases their health risks. It was observed that MWCs engaged in risky behaviours while at work. And in the interviews and focused group discussions, it was revealed that they engaged in risky behaviours such as smoking, drinking tea, and eating snacks and chewing betel leaves, lifting heavy items carelessly, occupying unsafe positions in the moving vehicles, while work. More than $60 \%$ of the respondents were consuming liquor and smoking cigarettes. There can be several reasons for adaption and continuation of risky behaviours. Arcury and Quandt (1998) noted that the beliefs such as that they are not being at risk can serve as a mechanism for disregarding risks associated with certain practices. The lack of peer pressure from intimates whom one admires, tend to induce one to engage in risky behaviours.

Pre-KAP survey also revealed that only a minority $(26 \%)$ of the respondents followed safe work practices such as usage of PPE during waste handling. The majority (73\%) of the respondents had not adopted safe work practices such as use of PPE, use of proper handling methods, and attend to personal health care, during waste collection. After the project interventions MWCs who engaged in risky work behaviours declined by $26 \%$, while their engagement in safe work behaviours rose by $10 \%$.

\section{Knowledge level on health and safety measures}

According to the pre KAP survey, only a minority (26\%) of respondents had a satisfactory level of knowledge on OSH. About one third of respondents (31\%) had a poor knowledge on health and safety measures (Table 2). This trend had previously been observed by Tucker (2003), who stated that the workers may lack knowledge unless relevant information such as consequences of exposure to OSH risks is not clearly communicated to them. The results show that majority of the respondents (Moderate $42.6 \%$ and Poor 31.4\%) had knowledge below the required level, to identify potential threats of their jobs and to follow preventive measures.

\section{Table 2. Level of knowledge}

\begin{tabular}{lcc}
\hline Knowledge Level & Before Project $\%$ & After Project \% \\
\hline Good & 26.0 & 76.0 \\
Moderate & 42.6 & 13.4 \\
Poor & 31.4 & 10.6 \\
\hline
\end{tabular}

According to Table 2, after the project interventions, there were more than three fourths $(76 \%)$ of the respondents having a good knowledge i.e. aware about the type of injuries, first aid, effects of waste burning, waste sorting and disposal methods, health and sanitary measures. According to the findings, the knowledge gained by the MWCs was very encouraging, and the outcomes of the training and awareness programmes were successful. 


\section{Attitudes of MWCs}

An attitude is defined as a state of mental readiness to act or respond. There were almost one third $(31 \%)$ of the respondents having negative attitudes towards the OSH measures while $40 \%$ of the respondents were neutral on the OSH measures before the project interventions (Table 3). Attitudes of the respondents with respect to food habits, alcohol consumption and smoking, use of PPE, occupational health hazards and job duties and responsibilities were considered in the study. The data gathered and summarized from the pre-KAP baseline survey revealed a lack of awareness about the seriousness of the risks associated with the occupation. Awareness creation among the respondents in-order to change their attitudes is very important, so that they would take care of themselves and adopt safe and better work practices while on the job.

Table 3. Attitudes towards OSH measures

\begin{tabular}{lcc}
\hline Attitudes & Before Project \% & After Project \% \\
\hline Positive & 28.7 & 36.7 \\
Neutral & 40.0 & 38.8 \\
Negative & 31.3 & 24.5 \\
\hline
\end{tabular}

According to Table 3 above, findings of pre and post-KAP survey data related to the respondent's attitudes on OSH measures and individual health concerns indicate an increase in positive attitudes and a decrease in negative attitudes. It shows that the number of respondents having positive attitudes rose by $8 \%$ while those with negative attitudes declined by $6 \%$. Findings presented in Table 4 shows that there is lack of awareness and proper attitudes about the seriousness of the risks associated with the occupation.

Table 4. Measurement of attitudes

\begin{tabular}{|c|c|c|c|c|c|c|}
\hline \multirow[b]{2}{*}{ Attitude } & \multicolumn{3}{|c|}{ Before Project \% } & \multicolumn{3}{|c|}{ After Project \% } \\
\hline & 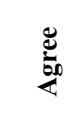 & 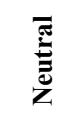 & 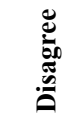 & 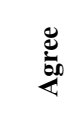 & $\frac{\bar{\pi}}{\tilde{\Xi}}$ & 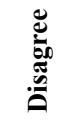 \\
\hline $\begin{array}{l}\text { There are no serious health hazards related to } \\
\text { waste collection }\end{array}$ & 40.9 & 37.4 & 21.7 & 13.0 & 28.7 & 58.3 \\
\hline $\begin{array}{l}\text { I need good health and safety conditions in the } \\
\text { work setting }\end{array}$ & 25.2 & 45.2 & 29.6 & 67.8 & 32.2 & 0.0 \\
\hline
\end{tabular}

Only a few $(21 \%)$ of the respondents believed that there are health hazards associated with waste collection before the project, but it rose to $58 \%$ after the project interventions. In the pre KAP survey, it was revealed that only one fourth of the respondents believed that they need improvements of OSH measures. After the project interventions, this figure rose to $67 \%$. According to the findings, the project inventions have positively changed MWC's attitudes, through creating awareness on health and safety conditions associated with waste collection. 


\section{Respondents' perceptions on PPE provided}

Respondents had mixed perceptions on PPE provided by the project. Majority of the respondents were keen to use the rain coats, and it was their most important requirement. Respondents' feel the raincoats are not hardy enough for heavy rains and they are not durable. The respondents' perceptions on overall uniform, gloves and safety helmets were satisfactory. There was no skin irritations reported due to fabrics used for making PPE. However, they were reluctant to wear the boots due to heat generated during hot humid days. Expert observations found that MWCs were wearing safety gears especially during night shifts. The usage of boots was not observed during day time collection except among the dumpsite workers. Even though the MWCs were keen to wear gloves, GMC has failed to provide frequent replacements for worn out gloves due to financial and administration issues. According to the MWCs, wearing protective clothing enhanced their dignity and self-image as well as to a certain extent improved their recognition both by the organization (i.e. GMC) and the general public in the area they served.

\section{CONCLUSIONS AND RECOMMENDATIONS}

Municipal solid waste collection is a challenge in any country. It is a task that demands various forms of support such as training and non-training interventions to enhance adoption of self-protective behaviours among the MWCs engaged in the MSW management. This study revealed that the MWCs in GMC have been able to improve their knowledge and attitudes, and adopt safe work practices due to the project interventions protecting them from potential occupational health and safety risks. Although MWCs are relatively old in age, they can benefit significantly by undergoing training designed on the basis of their real needs. The willingness to accept of PPE shows that potential occupational health risks can be reduced by using both training and non-training interventions. The MWC participants of the study were deeply concerned about the benefits they gained both from training sessions and opportunities to interact with resource persons. The participants weaned themselves from the feeling of being an alienated set of employees, and engaged in a not so respectable job. As a result of the project intervention they recognized their own social worth and thoughts that they are rendering an indispensable service for the benefit of themselves, their city, community and the environment.

The city administration should encourage and stimulate MWCs to work as an enthusiastic team by providing a congenial atmosphere for them. It is important to motivate the MWCs to use PPE using monetary or non-monitory benefits. It is recommended to properly direct overseers and other staff to maintain the MWCs with better OSH practices. Continuous supply of PPE is highly recommended to ensure both safety of workers and benefits to the society in-terms of a healthy environment for all, through getting the MWCs to do their tasks well. Frequent training sessions with suitable time intervals are recommended to increase the retention of knowledge among MWCs. It will also act as a motivation factor for continuing better OSH measures.

\section{ACKNOWLEDGEMENTS}

The Authors are most grateful to Canadian International Development Agency and the Association of Canadian Community Colleges for technical and financial support given for 
the Project. They are also grateful to Hon. Mayor, Commissioner and staff members of the GMC, members of the Niagara College (NC), Canada, Galle College of Technology (GCOT) SWMRU and Mr. I.M. Gunawardena for their support throughout the study period.

\section{REFERENCES}

Arcury, T.A. and Quandt, S.A. (1998). Occupational and environmental health risks in farm labour. Human Organ. 57, 331-334.

Biderman, D. (2010). Waste Business Journal.com; Industry Research and analysis [Online]. [Accessed on $03^{\text {rd }}$ February 2013]. Available at

http://www.wastebusinessjournal.com/news/wbj20100824A.htm

Cointreau, S. (2006). Sustainable solid waste management systems in developing countries [Online]. [Accessed on $7^{\text {th }}$ June 2014]. Available at http://siteresources.worldbank.org/INTUSWM/Resources/English_e-Sessions.pdf

Geer L.A., Curbow B.A., Anna D.H., Lees P.S.J., Buckley T.J. (2006). Development of a questionnaire to assess worker knowledge attitudes and perceptions underlying dermal exposure,. Scand J Work Env Hea. 32(3), 209-218.

ILO. (2009). International labour orgnization:Colombo; safty and health at work [Online]. [Accessed on $04^{\text {th }}$ April 2014]. Available at

http://www.ilo.org/colombo/areasofwork/safety-and-health-at-work/lang--en/index.htm

Ministry of Health Sri Lanka. (2011). Health services dilivery programme for vulnerable populations: Occupational health.

Mudalige, O.M.D.C.S. \& Dharmathilake, A.D. (2000). Health Problems Among Colombo Municipal Council Workers. Colombo, University of Colombo.

Mustajbegovic, J. Zuskin E., Schachter E.N., Kern, J., Vitale K., Ebling, Z., Vrcic-Keglevic, M. (2000). Respiratory findings in chemical workers exposed to low concentrations of organic and inorganic air pollutants. Am J Ind Med . 38(4), 431-440.

NIOSH. (1985). Occupational health and safety guildlence manual for hazardous waste site activities. Washinton DC: US Govenment Printing office.

OML. (2010). Health and Safety Training in the Workplace [Online]. [Accessed on $02^{\text {nd }}$ February 2014]. Available at http://www.labour.gov.on.ca/english/hs/prevention/report/index.php

Poulsen, O.M. Breum, N.O., Ebbehoj, N., Hansen, A.M., Ivens, U.I., Van Lelieveld, D., Malmros, P., Matthiassen, L., Nielsen, B.H., Nielsen, E.M., Schibye, B., Skov, T., Stenbaek, E.I., Wilkins, C.K., (1995) Collection of Household Waste, Review of Occupational Health problems and Their Possible Causes. Sci Total Environ. 170, 1-19. 
Robson, L. S., Clarke, J. A., Cullen, K., Bielecky, A., Severin, C., Bigelow, P. L., Irvin, E., Culyer, A., Mahood, Q. (2012). A systematic review of the effectiveness of occupational health and safety training. Scand J Work, Env and Hea. 38(3), 193 - 208.

Rozman, M.A., Alves, I.S., Porto, M.A., Gomes, P.O., Ribeiro, N.M., Nogueira, L.A., Caseiro, M.M., Silva, V.A., Massad, E., Burattini, M.N. (2008). HIV infection and related risk behaviors in a community of recyclable waste collectors of Santos, Brazil. Rev Saúde Pública. 42(5), 838-843.

Tucker, S.B. (2003). Prevention of occupational skin disease. Dermatoogicl Clinnics. 6(1), 87-96.

Wickramatillake, H. (2011). Occupational Health in South[Online]. [Accessed on $02^{\text {th }}$ February 2013]. Available at

http://www.collegiumramazzini.org/download/WICKRAMATILLAKE11.pdf 